\title{
Mining the Management Literature for Insights into Implementing Evidence-Based Change in Healthcare
}

\section{Tirer profit de la littérature sur la gestion pour trouver des pistes quant à la mise en ouvre de changements fondés sur les données probantes dans les services de santé}

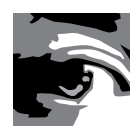

KAREN HARLOS, MA, PHD

Associate Professor E Inaugural Chair, Department of Business and Administration

University of Winnipeg

Winnipeg, $M B$

JACQUELINE TETROE, MA

Senior Policy Advisor, Knowledge Translation and Public Outreach

Canadian Institutes of Health Research

Ottawa, ON

IAN D. GRAHAM, MA, PHD

Vice-President, Knowledge Translation and Public Outreach

Canadian Institutes of Health Research

Ottawa, ON

MADELEINE BIRD, BA

Graduate Student, Département de médecine sociale et préventive

Université de Montréal

Montréal, QC

NICOLE ROBINSON, BA

Research Officer, National Aboriginal Health Organization

Ottawa, ON 


\title{
Karen Harlos et al.
}

\begin{abstract}
Objective: We synthesized the management and health literatures for insights into implementing evidence-based change in healthcare drawn from industry-specific data. Because change principles based on evidence often fail to be translated into organizational practice or policy, we sought studies at the nexus of organizational change and knowledge translation. Methods: We reviewed five top management journals to identify an initial pool of 3,091 studies, which yielded a final sample of 100 studies. Data were abstracted, verified by the original authors and revised before entry into a database. We employed a systematic narrative synthesis approach using words and text to distill data and explain relationships. We categorized studies by varying levels of relevance for knowledge translation as (1) primary, direct; (2) intermediate; and (3) secondary, indirect. We also identified recurring categories of change-related organizational factors. The current analysis examines these factors in studies of primary relevance to knowledge translation, which we also coded for intervention readiness to reflect how readily change can be implemented.

Preliminary Results and Conclusions: Results centred on five change-related categories: Tailoring the Intervention Message; Institutional Links/Social Networks; Training; Quality of Work Relationships; and Fit to Organization. In particular, networks across institutional and individual levels appeared as prominent pathways for changing healthcare organizations. Power dynamics, positive social relations and team structures also played key roles in implementing change and translating it into practice. We analyzed journals in which first authors of these studies typically publish, and found evidence that management and health sciences remain divided. Bridging these disciplines through research syntheses promises a wealth of evidence and insights, well worth mining in the search for change that works in healthcare transformation.
\end{abstract}

\section{Résumé}

Objectif: Nous avons effectué une synthèse de la littérature sur la gestion et sur la santé pour obtenir des pistes quant à la mise en œuvre de changements fondés sur les données probantes dans les services de santé, et ce, à partir de données propres au secteur d'activité. Puisque la transposition des principes du changement fondé sur les données probantes dans la pratique ou politique organisationnelles est souvent vouée à l'échec, nous avons tenté de comprendre les liens entre le changement organisationnel et la transposition des connaissances.

Méthodes: L'examen de cinq importantes revues de gestion nous a permis de repérer un bassin initial de 3091 études, desquelles nous avons tiré un échantillon final de 100 études. Les données ont été résumées, vérifiées par leurs auteurs et révisées avant d'être versées dans une base de données. Nous avons employé une démarche de synthèse narrative systématique au moyen de mots et de texte afin de raffiner les données et d'expliquer les relations. Nous avons catégorisé les études en fonction de différents niveaux de pertinence pour la transposition de connaissances, soit (1) primaire, direct; (2) intermédiaire; et (3) secondaire, indirect. Nous avons également repéré des catégories récurrentes des facteurs organisationnels liés au changement. La présente analyse examine ces facteurs dans des études de pertinence primaire pour la 
Mining the Management Literature for Insights into Implementing Evidence-Based Change in Healthcare

transposition de connaissances, que nous avons codifiées pour l'intervention afin d'indiquer à quel point le changement peut être mis en œuvre.

Résultats préliminaires et conclusions : Les résultats portent sur cinq catégories liées au changement : la conception du message d'intervention; les liens institutionnels et réseaux sociaux; la formation; la qualité des relations de travail et l'ajustement à l'organisation. En particulier, les réseaux au niveau des associations et des individus semblent représenter des voies importantes pour le changement dans les organismes de services de santé. Les dynamiques du pouvoir, les relations sociales positives et les structures d'équipe jouent également un rôle clé dans la mise en œuvre du changement et sa transposition dans la pratique. Nous avons analysé les revues où les premiers auteurs des études publient habituellement et nous avons trouvé des données qui indiquent que la gestion et les sciences de la santé demeurent divisées. La création de liens entre ces disciplines au moyen de synthèses pourrait donner lieu à un important fonds de données et de pistes dont il vaudrait la peine tirer profit pour favoriser un changement fonctionnel dans le contexte de la transformation de services de santé.

$\mathrm{I}$

N TODAY'S FAST-PACED HEALTHCARE SECTOR, ORGANIZATIONS AND SERVICES ARE highly fragmented with persistent problems in efficiency, quality of care and work-life quality (IOM 2003; Ramanujam and Rousseau 2006). Fortunately, management research can provide insights into the sources of problems as well as levers for improvement across organizational and clinical realms (Denis et al. 2011). For example, evidence of work conditions experienced by clinicians and administrators in Canada has led to normative policy and practice recommendations for reducing job strain and turnover (Harlos and Axelrod 2008; Lavoie-Tremblay et al. 2005; Shamian and El-Jardali 2007). Moreover, there is increasing evidence that implementing best practices and policies in healthcare workplaces leads to better patient care (e.g., West et al. 2006).

Workforce and work environment problems remain especially troubling, however, given the Institute of Medicine's (2000) groundbreaking conclusion that organizational factors more than individuals - underlie patient errors, most of which are preventable. This finding has spurred research on turning healthcare facilities into high-performance organizations through state-of-the-art management knowledge of human resources, work processes and systems, as well as a range of factors such as leadership and organizational culture, drawing on lessons from healthcare and other industries (e.g., Gittell 2009; Tamuz and Thomas 2006). Evidence-based change is now a strategic priority for health system improvement in many regions of the world (Ferlie and Shortell 2001; Iles and Sutherland 2001; Law et al. 2008), supported by mounting descriptions of successful transformation (Baker and Denis 2011).

Organizational change, however, is complex in theory and in practice. Defined as difference in function, form or membership, it can be episodic, discontinuous and planned, on the one hand, or continuous, incremental and emergent, on the other (Weick and Quinn 1999). 
Change thus can be implemented in a number of ways, each with varying degrees of success. To help healthcare organizations achieve gains - organizational and clinical - from change initiatives, decision-makers need to know what to change, how to implement change and how to translate research evidence into practice and policy (Law et al. 2008). Unfortunately, change principles based on research evidence often are not translated into organizational practice, leading to serious losses in efficiency, quality, productivity and other key performance indicators (IOM 2003; Ramanujam and Rousseau 2006; Straus et al. 2011).

\section{The Challenge of Evidence-Based Change in Healthcare}

Using research evidence for organizational change is challenging in healthcare contexts, which commonly combine multiple missions, professions and stakeholders who carry out tasks in complex, ambiguous and dynamic settings requiring local knowledge (Ramanujam and Rousseau 2006). Healthcare organizations of the 21st century are distinct from other organizations by the combination, volume and range of features they encompass (Nembhard et al. 2009). Complex adaptive systems theory provides one framework for understanding healthcare organizations (Begun et al. 2003; Plsek 2000). From a theoretical perspective, they comprise nested layers of subsystems that evolve emergently rather than purposefully, and function unpredictably in non-linear fashion. From a practical perspective, change management requires recognizing inherent tensions and paradoxes (e.g., control versus autonomy, competition versus collaboration) and artfully applying scientific evidence in these dynamic circumstances.

Unfortunately, strong boundaries between disciplines make it difficult to use research evidence for change purposes. Implementation research, which examines methods to promote the uptake of research findings into routine healthcare for clinical and policy purposes, makes scant use of theory from organizational, social and health sciences, ignoring benefits to innovation and interventions that such knowledge can provide (Davies et al. 2010). At the same time, sharp professional divisions stifle the extent to which evidence is sought, exchanged and applied. Ferlie and colleagues (2005), for example, found that strong boundaries across the range of professions comprising healthcare staff slow the spread of innovation. Health researchers and decision-makers also tend to neglect the management literature when looking for evidence regarding strategies for implementing change (Nicolini et al. 2008). This neglect may be due to limited awareness of, or access to, organizational journals. The challenges for healthcare professionals in finding, appraising and applying high-quality, relevant research evidence are well known and enduring (Kiefer et al. 2005; Lavis et al. 2003; Wathen et al. 2008). As a senior director of clinical services working with the first author observed, "Today's healthcare managers are barraged with information from internal and external resources. It is challenging to focus one's preparatory reading in anticipation of situations in which the research would apply. Decision-making is often required in emergent situations within healthcare, giving managers little time to complete fulsome reviews of literature in search of evidence."

Research syntheses are a relatively new but important way to aggregate evidence across organizational and health sciences and make it more accessible for managing healthcare work- 
places (Denis et al. 2011; Lomas 2005; Pope et al. 2006). By integrating and contextualizing research, cross-disciplinary syntheses support the exchange of ideas and identify knowledge gaps that can guide the production of tools or resources for knowledge use (Graham et al. 2006; Tricco et al. 2011). Although syntheses have begun to identify organizational factors related to successful healthcare-based change, such as leadership (Gifford et al. 2007), learning cultures (French et al. 2009) and patient care (Wensing et al. 2006), the extent to which such knowledge is applied is not well known. The turbulence and widespread challenges (e.g., financial, demographic, geographic) facing the health sector make syntheses of management research set in healthcare more important than ever before (Rousseau 2006; Walshe and Rundall 2001).

Increasingly, healthcare professionals seeking change want evidence grounded in the contemporary reality of healthcare, including its contextual complexities (Dopson and Fitzgerald 2005; Law et al. 2008). In this vein, the dean of a Canadian medical school warned the first author to shun off-the-shelf findings from other industries in her design of leadership training for healthcare leaders, who "don't want principles of manufacturing cherry Coke tacked on to hospital processes." Given the need for industry-specific data and the challenge of implementing evidence-based change in healthcare organizations, we wanted to identify relevant studies within a subset of the management literature. Our synthesis outlined change-related organizational factors and their relative implications for knowledge translation, including the extent to which change could be readily implemented. Our goal was to build on an analysis of planned action theories drawn from education, social science and health literatures (Graham and Tetroe 2007) that showed the importance of organizational factors in a knowledge-to-action process (Graham et al. 2006). Like the earlier study, we used the definition of knowledge translation provided by the Canadian Institutes of Health Research. ${ }^{1}$ Until recently, few studies have made explicit linkages between organizational change and knowledge translation (for an exception, see Kitson 2009), even though models and theories of knowledge translation are essentially models and theories of change (Graham and Tetroe 2007). The present study deals directly with these links in the context of healthcare organizations.

\section{Methods}

We began by conducting a comprehensive review of key management journals to identify relevant studies. We then organized and interpreted data in an exploratory review of evidence within and across studies. The broad scope of the review and diverse forms of evidence within it pointed to a systematic approach known as narrative synthesis as the prime method for integrating and describing preliminary findings. Narrative syntheses use words and text to distill data and explain relationships, and are a valid means of building a body of aggregated knowledge while recognizing barriers and facilitators to implementation (Arai et al. 2007; Mays et al. 2005; Rodgers et al. 2009). A flow chart summarizing the overall review and synthesis process is presented in Figure 1. 
FIGURE 1. Overview of the synthesis process

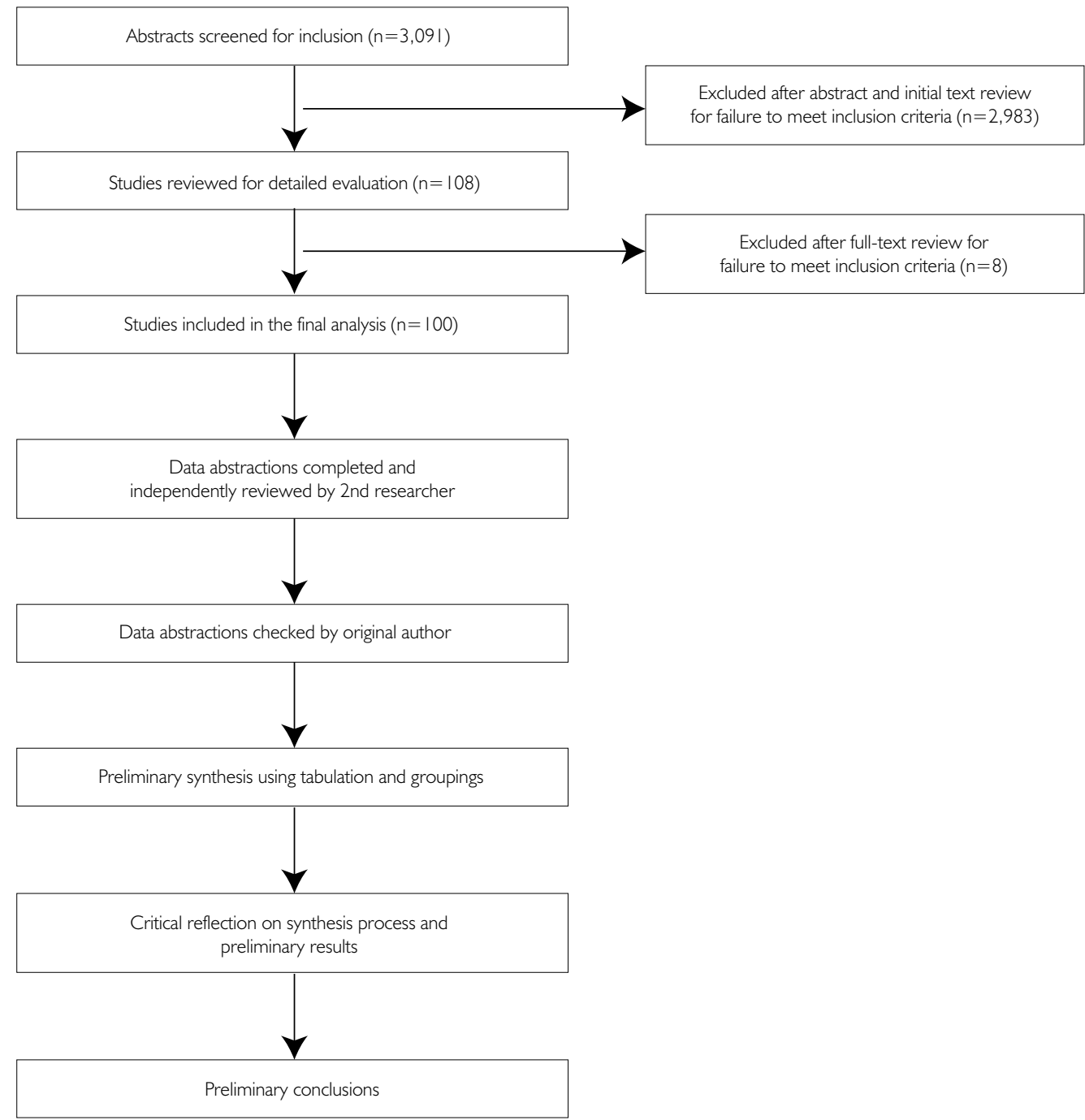

\section{Data and sample}

As indicated, we first selected five top management journals recognized worldwide for excellence through original, well-executed research (Association of Business Schools 2010; Podsakoff et al. 2005) to enhance the validity of our findings and their suitability for policy and practice recommendations. The journals for this study were Administrative Science Quarterly, Academy of Management Journal, Journal of Management Studies, Journal of Applied Psychology and Journal of Organizational Behavior. These journals originate in North America and Europe and publish work from a range of subject fields (e.g., general management, psychology, organization studies) whose scope includes theory-driven research on organizational change. We hand-searched the journals to identify studies published between 1996 and 2006 set in healthcare (or tested in a healthcare organization and reported elsewhere). We excluded 
studies that focused on factors that were not amenable to change (e.g., external environment). Of 3,091 studies, 108 were identified for inclusion after initial screening and detailed evaluation (see Figure 1). Another researcher reviewed each initial decision, and differences were resolved by discussion. This process yielded a final sample of 100 studies. Together, these studies reflected a variety of research traditions, from positivism to phenomenology, and of methods, from quantitative to qualitative. Nearly all studies tested theory-driven models or frameworks; only a handful were solely theoretical.

Data from each study were abstracted using the protocol from the prior foundational synthesis of planned change research from different disciplines. That protocol was shown to be a comprehensive and valid tool for organizing and interpreting data (Graham and Tetroe 2007). To enhance consistency and accuracy, each abstraction was independently examined by at least one study researcher, verified by the original authors and revised if needed before entry into a database. Few revisions were required. The database of individual abstractions from the prior and present synthesis, along with an electronic User's Guide (http://www.iceberg-grebeci.ohri. $\mathrm{ca} /$ research/kt_theories_db.html), has generated steady interest, having been accessed 2,935 times from March 2007 to April 2010.

\section{Analytic approach}

For our purposes, we examined data abstractions to identify naturally occurring groupings and clusters around which the synthesis could be organized. The most immediate difference among studies was the relative amenability for translating knowledge into action. We thus categorized studies according to knowledge translation relevance as follows: (1) primary, direct; (2) intermediate and (3) secondary, indirect. In broad terms, the first category refers to studies describing ways through which organizational structure and processes can be changed to support translation of research evidence into policy and practice. Studies within the intermediate relevance category tended to describe features of organizations that acted as barriers or facilitators for translating knowledge. In contrast, the secondary relevance category represented features that provided very limited potential for translating knowledge into action.

At this early stage of synthesis development, we used thematic analysis to identify systematically recurrent key concepts and the broader organizational factors they represent from the full set of studies in the sample. To determine organizational factors, we examined the conceptual underpinnings of studies within and across the three levels of knowledge translation relevance consistent with narrative synthesis techniques for developing preliminary syntheses (Arai et al. 2007). This process was a lengthy, iterative interrogation of the data and researchers' interpretations until consensus was reached. We then mapped studies according to core factors they represent. This mapping was made independently by two researchers and then jointly reviewed. Reviewer differences were resolved by discussion.

The current analysis examines these organizational factors in studies of primary relevance to knowledge translation, which we also coded for how readily change can be implemented or taken up into routine practice. To do so, we adapted the concept of intervention readiness from 
stages-of-change models for individuals and organizations (e.g., Prochaska and DiClemente 1983), which refers to how readily change can be implemented. The National Implementation Research Network uses this concept to index innovations by how grounded they are in stable models, how operationalized the models are and how able innovations are to be implemented (http://projectlaunch.promoteprevent.org/webfm_send/1629).

For our purpose, we categorized the primary relevance studies as high, medium or low in terms of readiness for intervention. High-readiness studies describe and test an intervention that facilitates uptake of findings. Such studies can be implemented without needing further model specification or empirical support. Medium-readiness studies describe an intervention but do not test it; findings have clear utility for guiding implementation. Low-readiness studies also describe but do not test an intervention; however, findings have limited utility and provide little information about implementation. As before, categorizations were made independently by two researchers and then jointly reviewed. Reviewer differences were resolved by discussion. Lastly, using this subset of studies we also conducted a preliminary citation analysis by examining journals in which first authors of these studies typically publish using the Web of Science citation index.

\section{Results and Conclusions}

From the synthesis process, 10 broad categories of organizational factors emerged: Tailoring the Intervention Message; Institutional Links/Social Networks; Training; Quality of Work Relationships; Fit to Organization; Person-Centred Characteristics; Job-Centred Characteristics; Work Attitudes; Turnover and Absenteeism; and Organizational Culture. Among studies with primary relevance to knowledge translation, we observed that only the first five of these factors were germane. Table 1 lists individual studies, the factors they represent and key concepts involved, along with intervention-readiness determinations.

Twenty studies with primary relevance to knowledge translation were classified according to the organizational factors they address, some of which were classified across two factors because of a dual focus. Four such studies were dual-categorized in this way, yielding 16 distinct studies in this grouping. The highest number of studies related to Tailoring the Intervention Message $(n=8)$, followed by Institutional Links/Social Networks ( $n=5)$, Training $(n=3)$, Quality of Work Relationships $(n=3)$ and Fit to Organization $(n=1)$. To our surprise, not one of the studies most relevant for knowledge translation had high readiness for intervention; that is, none described an intervention that had been tested. Instead, 9 of 20 studies in this grouping were deemed as medium readiness (i.e., clear implications for implementation), while the remaining 11 studies had low intervention readiness (i.e., indirect implications). The dependent variables of interest included organizational change (e.g., Dutton and Ashford 1993; Reay et al. 2006), innovation (e.g., Ferlie et al. 2005; West et al. 2006) and team learning (e.g., Edmondson 2003).

Together, studies related to tailoring messages, structuring and implementing networks, and devising training protocols highlight the role of linkage and exchange through stakeholders 
and other organizational conduits for translating knowledge into action. Both institutional- and individual-level networks feature prominently as pathways through which knowledge can be conveyed within and across healthcare organizations. These results are broadly consistent with past work highlighting the importance of multilevel networks in healthcare, such as that by Dopson (2007), who conceptualized networks as a contextual feature. The majority of studies on intervention messages, links and networks, and training were regarded as highly relevant to knowledge translation; only a few had either intermediate relevance $(n=2)$ or secondary relevance $(n=3)$.

TABLE 1. Change-related organizational factors, key concepts and implications for knowledge translation from studies of primary relevance to knowledge translation

\begin{tabular}{|c|c|c|c|}
\hline $\begin{array}{l}\text { Organizational } \\
\text { Factors }\end{array}$ & $\begin{array}{l}\text { Individual Studies } \\
\text { [intervention readiness*] }\end{array}$ & Key Concepts & $\begin{array}{l}\text { Implications for } \\
\text { Knowledge Translation }\end{array}$ \\
\hline $\begin{array}{l}\text { Tailoring the } \\
\text { Intervention } \\
\text { Message }\end{array}$ & $\begin{array}{l}\text { Allen, T.D., L.T. Eby and E. Lentz. 2006. } \\
\text { "Mentoring Behaviors and Mentorship } \\
\text { Quality Associated with Formal Mentoring } \\
\text { Programs: Closing the Gap Between } \\
\text { Research and Practice." Journal of Applied } \\
\text { Psychology 9I(3): 567-78. [2] } \\
\text { Dutton, J.E., S.J. Ashford, R.M. O'Neill and } \\
\text { K.A. Lawrence. 200 I. "Moves that Matter: } \\
\text { Issue Selling and Organizational Change." } \\
\text { Academy of Management Journal 44(4): } \\
\text { 7I6-36. [2] } \\
\text { Ferlie, E., L. Fitzgerald, M. Wood and } \\
\text { C. Hawkins. 2005. "The Nonspread } \\
\text { of Innovations: The Mediating Role of } \\
\text { Professionals." Academy of Management } \\
\text { Journal 48(I): I I7-34. [3] } \\
\text { Hoff, T.j., H. Pohl and J. Bartfield. 2006. } \\
\text { "Teaching But Not Learning: How Medical } \\
\text { Residency Programs Handle Errors." Journal of } \\
\text { Organizational Behaviour 27(7): 869-96. [2] } \\
\text { Katz-Navon, T., E. Naveh and Z. Stern. } \\
\text { 2005. "Safety Climate in Health Care } \\
\text { Organizations: A Multidimensional } \\
\text { Approach." Academy of Management Journal } \\
48(6): \text { I075-89. [3] } \\
\text { Neal, A. and M.A. Griffin. 2006. "A Study } \\
\text { of the Lagged Relationships Among Safety } \\
\text { Climate, Safety Motivation, Safety Behavior } \\
\text { and Accidents at the Individual and Group } \\
\text { Levels." Journal of Applied Psychology 9I (4): } \\
\text { 946-53. [3] } \\
\text { Reay, T., K. Golden-Biddle and K. Germann. } \\
\text { 2006. "Legitimizing a New Role: Small Wins } \\
\text { and Microprocesses of Change." Academy of } \\
\text { Management Journal 49(5): 977-98. [2] } \\
\text { West, M.A. and N.R. Anderson. I996. } \\
\text { "Innovation in Top Management Teams." } \\
\text { Journal of Applied Psychology 8I(6): 680-93. [2] }\end{array}$ & $\begin{array}{l}\text { Support for innovation } \\
\text { Team structure, process and } \\
\text { characteristics (e.g., size, member } \\
\text { tenure, proportion of innovators) } \\
\text { Knowledge of organizational } \\
\text { context } \\
\text { Communication } \\
\text { Professionals: } \\
\text { Communities of practice } \\
\text { Boundaries (social and cognitive) } \\
\text { Safety climate } \\
\text { Role creation, adaption and } \\
\text { legitimation } \\
\text { Mentoring behaviours and quality } \\
\text { Barriers and best practices to } \\
\text { learning from medical errors }\end{array}$ & $\begin{array}{l}\text { Effective knowledge } \\
\text { translation in healthcare } \\
\text { organizations relies on } \\
\text { planned tailoring and } \\
\text { delivery of messages } \\
\text { that account for the } \\
\text { roles of individuals (e.g., } \\
\text { knowledge brokers, } \\
\text { influence agents and } \\
\text { other members), } \\
\text { organizational climate } \\
\text { and structural features, } \\
\text { as well as hierarchical } \\
\text { power patterns in initiating } \\
\text { change (i.e., top-down vs. } \\
\text { bottom-up) }\end{array}$ \\
\hline
\end{tabular}


TABLE 1. Continued

\begin{tabular}{|c|c|c|c|}
\hline $\begin{array}{l}\text { Institutional } \\
\text { Links/Social } \\
\text { Networks }\end{array}$ & $\begin{array}{l}\text { Ferlie et al. 2005. (See Tailoring the } \\
\text { Intervention Message) } \\
\text { Gittell, J.F. and L. Weiss. 2004. } \\
\text { "Coordination Networks within and across } \\
\text { Organizations: A Multi-Level Framework." } \\
\text { Journal of Management Studies 4I(I): } \\
\text { I28-53. [2] } \\
\text { Goes, J.B. and S.H. Park. I997. } \\
\text { "Interorganizational Links and Innovation: } \\
\text { The Case of Hospital Services." Academy of } \\
\text { Management Journal 40(3): 673-96. [2] } \\
\text { Provan, K.G. and J.G. Sebastian. 1998. } \\
\text { "Networks within Networks: Service } \\
\text { Link Overlap, Organizational Cliques } \\
\text { and Network Effectiveness." Academy of } \\
\text { Management Journal 4I (4): 453-63. [3] } \\
\text { Westphal, J.D., R. Gulati and S.M. Shortell. } \\
\text { I997. "Customization or Conformity? An } \\
\text { Institutional and Network Perspective on } \\
\text { the Content and Consequences of TQM } \\
\text { Adoption. Administrative Science Quarterly } \\
42(2): 366-94 . \text { [3] }\end{array}$ & $\begin{array}{l}\text { Intra-organizational and } \\
\text { inter-organizational linkages, } \\
\text { coordination mechanisms, } \\
\text { integration and networks } \\
\text { Innovation support through } \\
\text { adoption of new services and } \\
\text { technologies } \\
\text { Timing of innovation adoption } \\
\text { Stage of adopters (early vs. late) } \\
\text { Institutional ties }\end{array}$ & $\begin{array}{l}\text { Knowledge translation } \\
\text { capacity in health } \\
\text { organizations is built by } \\
\text { coordinated institutional } \\
\text { and individual networks of } \\
\text { knowledge users within } \\
\text { and across organizational } \\
\text { units, which can act as } \\
\text { dissemination vehicles }\end{array}$ \\
\hline Training & $\begin{array}{l}\text { Allen and Lentz 2006. (See Tailoring the } \\
\text { Intervention Message) } \\
\text { Goodrick, E. and G.R. Salanick. I } 996 . \\
\text { "Organizational Discretion in Responding } \\
\text { to Institutional Practices: Hospitals and } \\
\text { Cesarean Births." Administrative Science } \\
\text { Quarterly 4I(I): I-28. [2] } \\
\text { Hoff et al. 2006. (See Tailoring the } \\
\text { Intervention Message) }\end{array}$ & $\begin{array}{l}\text { Mentoring behaviours and quality } \\
\text { Clarity of practice guidelines } \\
\text { Barriers and best practices for } \\
\text { learning from medical errors }\end{array}$ & $\begin{array}{l}\text { Clear standards and targets } \\
\text { for training to induce } \\
\text { change enhances uptake } \\
\text { Mentoring as a means } \\
\text { of training supports } \\
\text { knowledge translation } \\
\text { provided that power } \\
\text { relations do not inhibit } \\
\text { interpersonal exchange }\end{array}$ \\
\hline $\begin{array}{l}\text { Quality of Work } \\
\text { Relationships }\end{array}$ & $\begin{array}{l}\text { Edmondson, A.C. 2003. "Speaking Up in } \\
\text { the Operating Room: How Team Leaders } \\
\text { Promote Learning in Interdisciplinary Action } \\
\text { Teams." Journal of Management Studies } \\
\text { 40(6): I4I9-52. [2] } \\
\text { Nembhard, I.M. and A.C. Edmondson. } \\
\text { 2006. "Making It Safe: The Effects of Leader } \\
\text { Inclusiveness and Professional Status on } \\
\text { Psychological Safety and Improvement } \\
\text { Efforts in Health Care Teams." Journal of } \\
\text { Organizational Behaviour 27(7): 94I-66. [3] } \\
\text { West and Anderson 1996. (See Tailoring the } \\
\text { Intervention Message) }\end{array}$ & $\begin{array}{l}\text { Support for innovation } \\
\text { Team structure, process and } \\
\text { characteristics (e.g., preparation, } \\
\text { stability, boundary spanning, } \\
\text { team leader coaching, leader } \\
\text { inclusiveness) } \\
\text { Information infrastructure } \\
\text { Professional rank, status (i.e., } \\
\text { power) differences } \\
\text { Communication and exchange }\end{array}$ & $\begin{array}{l}\text { Key for effective } \\
\text { knowledge translation in } \\
\text { healthcare organizations } \\
\text { is support for innovation, } \\
\text { fostered by clear rationales } \\
\text { for change, open exchange } \\
\text { despite power differences, } \\
\text { and employee engagement }\end{array}$ \\
\hline Fit to Organization & $\begin{array}{l}\text { Dukerich, J.M., B.R. Golden and S.M. } \\
\text { Shortell. 2002. "Beauty Is in the Eye of the } \\
\text { Beholder: The Impact of Organizational } \\
\text { Identification, Identity and Image on the } \\
\text { Cooperative Behaviors of Physicians." } \\
\text { Administrative Science Quarterly 47(3): } \\
\text { 507-33. [3] }\end{array}$ & $\begin{array}{l}\text { Strength of perceived } \\
\text { organizational identity } \\
\text { Perceived image of organization }\end{array}$ & $\begin{array}{l}\text { Knowledge translation } \\
\text { is enhanced through } \\
\text { cooperation when health } \\
\text { professionals positively } \\
\text { perceive and identify with } \\
\text { the organization }\end{array}$ \\
\hline
\end{tabular}

\footnotetext{
* Intervention readiness: $1=$ high; $2=$ medium; $3=$ low
} 
Across several categories, including Quality of Work Relationships, power dynamics reflected in hierarchical position, position rank or professional status differences were shown to influence translation mechanisms and capacity. Specifically, ensuring that power differences do not inhibit open exchange of ideas and information was a key theme within studies related to Quality of Work Relationships. Of particular importance were findings indicating that team leaders play a central role in minimizing power differences to foster communication and the use of new practices (Edmondson 2003). In this regard the notion of leader inclusiveness, defined as words and deeds that indicate an invitation and appreciation for others' contributions (Nembhard and Edmondson 2006), was shown to be effective. It is worth noting, however, that most studies in the Quality of Work Relationships category had intermediate $(n=14)$ or secondary relevance $(n=13)$ for translating knowledge into action. A detailed analysis of barriers, facilitators and proximal influences on translating knowledge is beyond the scope of the current study however, summative findings suggest that a psychosocial work environment in which health professionals feel supported by supervisors, co-workers and the organization enhances knowledge exchange and uptake through a creative, committed workforce that perceives work relationships positively.

More broadly, in today's team-based healthcare work environments it is not surprising that teams appear to be a key structural configuration supporting knowledge translation in this set of studies. Although organizations rely on productivity and innovation gains from teamwork, losses can occur from increased conflict and decreased personal responsibility among members (De Dreu and Weingart 2003). Thus, leading and managing healthcare teams to build and preserve positive work relations is central to knowledge translation. In teams and elsewhere, the need for support from managers for introducing improved practices and procedures (i.e., support for innovation) was noteworthy. Overall, current findings reinforce the prominent role of social relations reported in past research on knowledge exchange between academics and practitioners (for a review, see Rynes et al. 2001), affirming Rogers's (1995) important observation that knowledge translation essentially is a social process.

Lastly, results of the citation analysis examining journals in which authors of studies with primary relevance to knowledge translation typically publish indicate that they publish almost exclusively in the management literature (see Table 2). These patterns provide further evidence (beyond that noted earlier) of the disciplinary divide between management sciences and health sciences. Such divisive boundaries limit the use of management evidence for organizational and clinical improvements in healthcare.

\section{Limitations and future research}

We offer these preliminary results as a fruitful starting point for additional study that might broaden the range of change-related organizational factors considered relevant to knowledge translation. We also hope this information will deepen these factors' conceptual underpinnings for better use of evidence-based change rooted in the real-world complexities of the health sector. We caution, however, that our results were gleaned from a knowledge synthesis, and there 
TABLE 2. Citation analysis of first authors of studies with primary relevance to knowledge translation

\begin{tabular}{|c|c|c|c|c|c|c|c|c|c|c|c|c|c|}
\hline First Author & 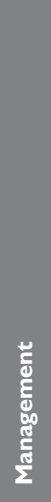 & 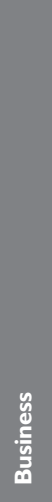 & 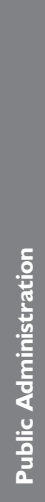 & $\begin{array}{l}\text { के } \\
\frac{0}{0} \\
\frac{5}{0} \\
0 \\
0\end{array}$ & 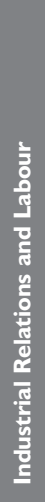 &  & 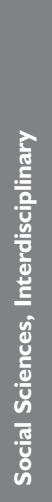 & 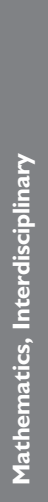 & $\begin{array}{l}\frac{\grave{g}}{\tilde{\sigma}} \\
\frac{\pi}{2}\end{array}$ & 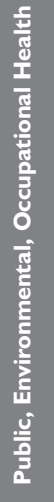 & 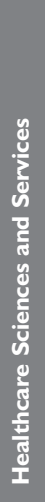 & 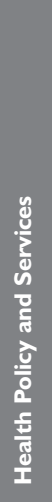 & $\frac{\frac{n}{n}}{\frac{5}{2}}$ \\
\hline Allen & 10 & 8 & & 12 & 1 & & & 1 & & & & & \\
\hline Dukerich & 44 & 29 & & 22 & & & & & 4 & & & & \\
\hline Dutton & 1 & & & & & & & & & & 8 & 6 & \\
\hline Edmondson & 34 & 17 & & 18 & & & & & & & & & \\
\hline Ferlie & 23 & 10 & 7 & & & & & & & & 14 & 18 & \\
\hline Gittel & 12 & 1 & & & & & & & 10 & 2 & 2 & 2 & \\
\hline Goes & 35 & 26 & & 5 & & & 2 & & 4 & & 8 & 14 & 2 \\
\hline Goodrick & 37 & 22 & & & & 4 & & & & 4 & & 3 & \\
\hline Hoff & 1 & 1 & & 2 & & & & & & & & 1 & 1 \\
\hline Katz-Novan & 11 & 4 & & 7 & & & 2 & & 9 & 4 & 6 & & 2 \\
\hline Neal & 7 & 5 & & 9 & & & 9 & 1 & 11 & & 3 & 4 & \\
\hline Nembhard & 6 & 3 & & 3 & & & & & & & & 9 & 3 \\
\hline Provan & 12 & 7 & 12 & 2 & & & & & & & & 4 & \\
\hline Reay & 11 & 6 & & & & & 1 & & 3 & & 1 & 1 & \\
\hline West & 58 & 32 & & 62 & & & & & & & & & \\
\hline Westphal & & 1 & & & & & & & & & & & \\
\hline
\end{tabular}

is the potential for bias in all syntheses. In this instance, it is possible that conclusions might vary if a different set of target journals were used. However, the sampling approach here is intended to be a comprehensive, rather than an exhaustive, search for high-quality management knowledge grounded in the contemporary realities of healthcare settings. At the same time, feasibility concerns precluded systematic searching beyond the pool of 3,091 studies across the 10-year time frame of five journals with full issue reviews. Our synthesis process of handsearching each issue over the sampling period, abstracting data from each study, confirming the accuracy of abstractions with authors, and preparing the database is labour intensive and 
costly. Narrative syntheses may also run the risk of over-interpretation of study data (Rodgers et al. 2009). We applied several safeguards to mitigate this risk, such as pre-specified inclusion criteria, a clearly defined process of synthesis, checks with authors to verify data accuracy, and checks with second researchers in iterative, critical appraisals until consensus was reached.

Despite its limits, this body of evidence is a useful launch for expanded journal searches across extended time periods (e.g., 2007-2012) to compare whether our findings are simply an effect of sampling. Thus, although the lack of intervention studies in this synthesis may be an artifact of journal sampling, it might reflect an actual gap in the management literature. This possibility could be explored in future work on an expanded set of journals or time periods. If the gap is genuine, it is interesting that the health literature related to implementation tends to pay considerably more attention to interventions than contexts in which they are applied (Graham and Tetroe 2007), a reverse of the tendency noted in the management literature.

The combination, volume and range of challenges facing healthcare have begun to set a new agenda for organizational research - to determine the features that help or hinder change in healthcare contexts and how this occurs. Further analyses from this and future syntheses are needed for insights into barriers, facilitators and indirect influences on knowledge translation for maximum impact of change efforts. Together, findings would inform a needed integrative framework for holistic, nuanced approaches to evidence-based change (Dopson 2007), offering ways to reconstitute core practices and policies governing how health organizations function that can be tested in local contexts.

We hope this work inspires additional efforts to integrate management and healthcare sciences and encourage each cadre of scientists to read and publish in both literatures. Bridging these disciplines through research syntheses promises a wealth of evidence and insights, well worth mining in the search for change that works in healthcare transformation. Such steps would bolster the study of methods to promote the use of research findings while helping decision-makers to determine what to change, how to implement change and how to translate research evidence into practice and policy.

\section{ACKNOWLEDGEMENTS}

We thank Jo Logan for her contribution to the conceptual design of the study, which included guiding the article inclusion criteria. We also thank Julia Baxter for verifying data abstractions with original authors and Darcy Ammerman for examining and revising data abstractions. We acknowledge the support of the Canadian Institutes of Health Research for funding this study (FRN 49285). Some analysis was completed while the first author was at University of Northern British Columbia, working with the Rural and Northern Practice Research Program (School of Nursing) and Dr. Martha MacLeod, whose commitment to researchpractice collaboration is inspiring. Portions of findings were presented at the KT08 Forum (Knowledge Translation: Forum for the Future) in Banff, Alberta. The authors are grateful to reviewers of this manuscript for helpful comments and to Davide Nicolini and Michel Wensing for comments on an earlier version. 
Correspondence may be directed to: Karen Harlos, Associate Professor and Inaugural Chair, Department of Business and Administration, University of Winnipeg, 515 Portage Ave., Winnipeg, MB, Canada R3B 2E9; tel: 204-789-1404; fax: 204-772-4183; e-mail:ka.harlos@uwinnipeg.ca.

\section{NOTE}

${ }^{1}$ According to this definition, knowledge translation is "a dynamic and iterative process that includes synthesis, dissemination, exchange and ethically sound application of knowledge to improve the health of Canadians, provide more effective health services and products and strengthen the health care system" (http://www.cihr-irsc. gc.ca/e/29418.html).

\section{REFERENCES}

Arai, L., N. Britten, J. Popay, H. Roberts, M. Petticrew, M. Rodgers and A. Sowden. 2007.“Testing Methodological Developments in the Conduct of Narrative Synthesis: A Demonstration Review of Research on the Implementation of Smoke Alarm Interventions." Evidence E Policy 3: 361-83.

Association of Business Schools. 2010. The Association of Business Schools Academic Journal Quality Guide. London, UK: Author. Retrieved June 11, 2012. <http://www.associationofbusinessschools.org/node/1000257> .

Baker, R. and J.-L. Denis. 2011. A Comparative Study of Three Transformative Healthcare Systems: Lessons for Canada. Ottawa: Canadian Health Services Research Foundation.

Begun, J., B. Zimmerman and K. Dooley. 2003. “Health Care Organizations as Complex Adaptive Systems." In S. Mick and M. Wyttenbach, eds., Advances in Health Care Organization Theory (pp. 253-88). San Francisco: JosseyBass.

Davies, P., A. Walker and J. Grimshaw. 2010. “A Systematic Review of the Use of Theory in the Design of Guideline Dissemination and Implementation Strategies and Interpretation of the Results of Rigorous Evaluations." Implementation Science 5(1): 14.

De Dreu, C. and L. Weingart. 2003.“Task versus Relationship Conflict, Team Performance, and Team Member Satisfaction: A Meta-Analysis." Journal of Applied Psychology 88: 741-49.

Denis, J.-L., H. Davies, E. Ferlie and L. Fitzgerald. 2011. Assessing Initiatives to Transform Healthcare Systems: Lessons for the Canadian Healthcare System. Ottawa: Canadian Health Services Research Foundation.

Dopson, S. 2007. “A View from Organizational Studies.” Nursing Research 56(4): 72-77.

Dopson, S. and L. Fitzgerald, eds. 2005. Knowledge to Action? Evidence-Based Health Care in Context. Oxford: Oxford University Press.

Dutton, J. and S. Ashford. 1993. “Selling Issues to Top Management." Academy of Management Review 18: 397-428.

Edmondson, A. 2003. "Speaking Up in the Operating Room: How Team Leaders Promote Learning in Interdisciplinary Action Teams." Journal of Management Studies 40: 1419-52.

Ferlie, E., L. Fitzgerald, M. Wood and C. Hawkins. 2005.“The Nonspread of Innovations: The Mediating Role of Professionals." Academy of Management Journal 48: 117-34.

Ferlie, E. and S. Shortell. 2001. "Improving the Quality of Health Care in the United Kingdom and the United States: A Framework for Change." Milbank Quarterly 79(2): 281-315.

French, B., L. Thomas, P. Baker, C. Burton, L. Pennington and H. Roddam. 2009.“What Can Management Theories Offer Evidence-Based Practice? A Comparative Analysis of Measurement Tools for Organisational Context." Implementation Science 4(1): 28.

Gifford, W., B. Davies, N. Edwards, P. Griffin and V. Lybanon. 2007. “Managerial Leadership for Nurses' Use of Research Evidence: An Integrative Review of the Literature." Worldviews on Evidence-Based Nursing 4(3): 126-45. Gittell, J. 2009. High-Performance Healthcare: Using the Power of Relationships to Achieve Quality, Efficiency and Resilience. New York: McGraw-Hill. 
Graham, I., J. Logan, M. Harrison, S. Straus, J. Tetroe, W. Caswell and N. Robinson. 2006. “Lost in Translation: Time for a Map?" Journal of Continuing Education in the Health Professions 26(1): 13-26.

Graham, I. and J. Tetroe. 2007. "Some Theoretical Underpinnings of Knowledge Translation." Academic Emergency Medicine 14(11): 936-41.

Harlos, K. and L. Axelrod. 2008. “Work Mistreatment and Hospital Administrative Staff: Policy Implications for Healthier Workplaces." Healthcare Policy 4(1): 40-50.

Iles, V. and K. Sutherland. 2001. Managing Change in the NHS: Organisational Change. A Review for Health Care Managers, Professionals and Researchers. London: National Coordinating Centre for NHS Service Delivery and Organisation.

Institute of Medicine (IOM). 2000. To Err Is Human: Building a Safer Health System. Washington, DC: National Academies Press.

Institute of Medicine (IOM). 2003. Priority Areas for National Action: Transforming Healthcare Quality. Washington, DC: National Academies Press.

Kiefer, L., J. Frank, E. Di Ruggiero, M. Dobbins, D. Manuel, P. Gully and D. Mowat. 2005. “Fostering EvidenceBased Decision-Making in Canada." Canadian Journal of Public Health 96(3): I1-I19.

Kitson, A. 2009. “The Need for Systems Change: Reflections on Knowledge Translation and Organizational Change." Journal of Advanced Nursing 65(1): 217-28.

Lavis, J.N., D. Robertson, J.M. Woodside, C.B. McLeod and J. Abelson. 2003. “How Can Research Organizations More Effectively Transfer Research Knowledge to Decision Makers?” Milbank Quarterly 81(2): 221-48.

Lavoie-Tremblay, M., R. Bourbonnais, C. Viens, M. Vezina, P. Durand and L. Rochette. 2005. “Improving the Psychosocial Work Environment." Journal of Advanced Nursing 49: 655-64.

Law, S., C. Flood and D. Gagnon for the Listening for Directions III Partners. 2008. Listening for Direction III. National Consultation on Health Services and Policy Issues for 2007-2010. Ottawa: Canadian Health Services Research Foundation.

Lomas, J. 2005. “Using Research to Inform Healthcare Managers' and Policy Makers' Questions: From Summative to Interpretive Synthesis." Healthcare Policy 1: 55-68.

Mays, N., C. Pope and J. Popay. 2005. "Systematically Reviewing Qualitative and Quantitative Evidence to Inform Management and Policy-Making in the Health Field." Journal of Health Services Research Policy 10 (Suppl. 1): 6-20.

Nembhard, I. and A. Edmondson. 2006. "Making It Safe: The Effects of Leader Inclusiveness and Professional Status on Psychological Safety and Improvement Efforts in Health Care Teams." Journal of Organizational Behavior 27: 941-66.

Nembhard, I.M., J.A. Alexander, T.J. Hoff and R. Ramanujam. 2009. “Why Does the Quality of Health Care Continue to Lag? Insights from Management Research." Academy of Management Perspectives 23(1): 24-42.

Nicolini, D., J. Powell, P. Conville and L. Martinez-Solano. 2008. “Managing Knowledge in the Healthcare Sector." International Journal of Management Reviews 10(3): 245.

Plsek, P. 2000. “Appendix B: Redesigning Health Care with Insights from the Science of Complex Adaptive Systems." In Crossing the Quality Chasm: A New Health System for the 21st Century (pp. 309-22). Washington, DC: Institute of Medicine/National Academies of Science.

Podsakoff, P., S. MacKenzie, D. Bachrach and N. Podsakoff. 2005. "The Influence of Management Journals in the 1980s and 1990s." Strategic Management Journal 26(5): 473-88.

Pope, C., N. Mays and J. Popay. 2006."Informing Policy Making and Management in Healthcare: The Place for Synthesis." Healthcare Policy 1(2): 43-48.

Prochaska, J. and C. DiClemente. 1983. “Stages and Processes of Self-Change of Smoking: Toward an Integrative Model of Change." Journal of Consulting and Clinical Psychology 51(3): 390-95.

Ramanujam, R. and D. Rousseau. 2006. “The Challenges Are Organizational, Not Just Clinical.” Journal of Organizational Behavior 27: 811-27.

Reay, T., K. Golden-Biddle and K. Germann. 2006. "Legitimizing a New Role: Small Wins and Microprocesses of Change." Academy of Management Journal 49: 977-98. 


\section{Karen Harlos et al.}

Rodgers, M., A. Sowden, M. Petticrew, L. Arai, H. Roberts, N. Britten and J. Popay. 2009.“Testing Methodological Guidance on the Conduct of Narrative Synthesis in Systematic Reviews." Evaluation 15: 49-74.

Rogers, E.M. 1995. Diffusion of Innovations. New York: Free Press.

Rousseau, D. 2006. "Is There Such a Thing As 'Evidence-Based Management'?" Academy of Management Review 31(2): 256-69.

Rynes, S., J. Bartunek and R. Daft. 2001.“Across the Great Divide: Knowledge Creation and Transfer Between Practitioners and Academics." Academy of Management Journal 44: 340-55.

Shamian, J. and F. El-Jardali. 2007."Healthy Workplaces for Health Workers in Canada: Knowledge Transfer and Uptake in Policy and Practice." HealthcarePapers 7(Special): 6-25.

Straus, S., J. Tetroe and I. Graham. 2011. “Knowledge Translation Is the Use of Knowledge in Health Care Decision Making." Journal of Clinical Epidemiology 64: 6-10.

Tamuz, M. and R. Thomas. 2006. “Classifying and Interpreting Threats to Patient Safety in Hospitals: Insights from Aviation." Journal of Organizational Behavior 27: 919-40.

Tricco, A., J. Tetzlaff and D. Moher. 2011. “The Art and Science of Knowledge Synthesis.” Journal of Clinical Epidemiology 64: 11-20.

Walshe, K. and T. Rundall. 2001."Evidence-Based Management: From Theory to Practice in Health Care." Milbank Quarterly 79(3): 429-57.

Wathen, C., G. Watson, S. Jack, S. Caldwell and N. Lewis. 2008. “From Big to Small: A Process for Developing Policy Relevant Research Summaries." Healthcare Policy 4(1): 60-69.

Weick, K. and R. Quinn. 1999. “Organizational Change and Development.” Annual Review of Psychology 50: 361-86.

Wensing, M., H. Wollersheim and R. Grol. 2006. “Organizational Interventions to Implement Improvements in Patient Care: A Structured Review of Reviews." Implementation Science 1: 2. doi: 10.1186/1748-5908-1-2.

West, M., J. Guthrie, J. Dawson, C. Borrill and M. Carter. 2006. “Reducing Patient Mortality in Hospitals: The Role of Human Resource Management." Journal of Organizational Behavior 27: 983-1002. 